\title{
Coronary-coronary free internal thoracic artery graft on a single, distal, left anterior descending artery lesion
}

\author{
Duško Nežić, MD, PhD, FETCS, Aleksandar Knežević, MD, BCh, Saša Borović, MD, Milan \\ Ćirković, MD, and Predrag Milojević, MD, BCh, FETCS, Belgrade, Serbia and Montenegro
}

A

free short segment of left internal thoracic artery (ITA) has been used to bypass a single distal lesion on a large left anterior descending artery (LAD) running well over the cardiac apex. In our opinion this technique occasionally might be an attractive approach for bypassing very distal lesions of large coronary arteries (combined with regular arterial or venous grafting if there has also been proximal stenosis in the targeted artery). The proximal remnant of the left ITA can be easily used as an in situ graft.

\section{Clinical Summary}

A 41-year-old man was admitted with progressive angina (New York Heart Association class III on admission) not relieved by optimal medical therapy. The result of a previous stress test was strongly positive. Cardiac catheterization and angiocardiography revealed good left ventricular function (ejection fraction of 0.55 ) with severe triple-vessel disease. There was occlusion of the right coronary artery, a 75\% stenosis of the ramus intermedius, and a long ( $3 \mathrm{~cm}$ in length) up to $95 \%$ stenosis (inconvenient for percutaneous transvenous coronary angioplasty) on the border zone between the mid and distal third of the large LAD (Figure 1).

Bypass surgery with the left ITA and a vein graft was planned and accomplished. The vein graft bypassed the right system (distal anastomosis was performed on the posterior descending branch). Because there was no proximal stenosis on the LAD, we decided to use only a short free segment of the left ITA to perform a coronary-coronary bypass (proximal and distal connections were done as terminolateral anastomoses) over that single distal stenosis. We have also grafted the ITA in situ onto the ramus intermedius. The aortic crossclamp time was 41 minutes.

The heart returned spontaneously to sinus rhythm, and the patient was weaned from cardiopulmonary bypass easily. The patient's postoperative course and convalescence progressed without any difficulty, and he was discharged with no angina. A predischarge check angiogram done on the 10th postoperative day

\footnotetext{
From the Department of Cardiac Surgery, Dedinje Cardiovascular Institute, Belgrade, Serbia and Montenegro.

Received for publication Oct 14, 2003; accepted for publication Nov 3, 2003.

Address for reprints: Duško Nežić, MD, PhD, FETCS, Department of Cardiac Surgery, Dedinje Cardiovascular Institute, M. Tepića 1, 11040 Belgrade, Serbia and Montenegro (E-mail: nezic@EUnet.yu).

J Thorac Cardiovasc Surg 2004;127:1517-8

$0022-5223 / \$ 30.00$

Copyright $\odot 2004$ by The American Association for Thoracic Surgery

doi:10.1016/j.jtcvs.2003.11.022
}

showed a patent free left ITA graft (Figure 2). The caliber of the left ITA matched that of the native $\mathrm{LAD}$, and it might be difficult to appreciate the presence of a con-

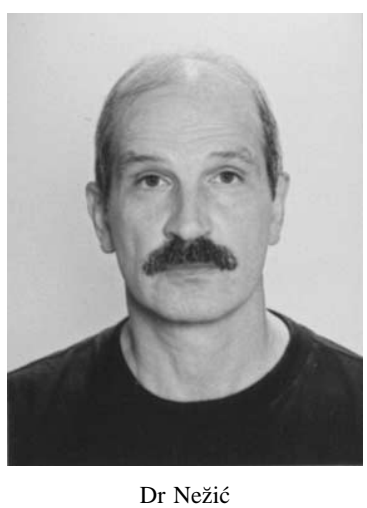
duit in the coronary circulation because the left ITA looks like the native coronary artery. The patient has been receiving regular follow-up for 6 months and is in New York Heart Association class I with a normal stress test result.

\section{Discussion}

Primarily used in the beginning of aortal-coronary bypass surgery (terminoterminal interposition of the greater saphenous vein between 2 parts of the resected coronary artery), ${ }^{1}$ coronary-coronary bypass grafting was revised by Biglioli and colleagues, ${ }^{2}$ and from a hemodynamic point of view, the physiologic restoration of coronary blood flow has been confirmed. Furthermore, progression of coronary disease at the site of the proximal anastomosis (the most critical point of this technique) has never been observed in a large series (143 patients, total of 148 coronary-coronary bypass grafts) undergoing coronary-coronary bypass grafting (Nottin and colleagues $^{3}$ ) at a maximum follow-up of 7 years. These results have confirmed the capability of coronary-coronary bypass grafting to play an important role in solving some difficult problems in coronary surgery (patients with porcelain aorta or heavily calcified ascending aorta, arch and supra-aortic branches, or cases in which there is inadequate length of available graft material). ${ }^{4,5}$ In these cases proximal and distal anastomoses can be achieved either between 2 segments of the same coronary artery or between 2 different coronary arteries.

In our case there was no proximal stenosis on the LAD, and thus we decided to use only a short free segment of the left ITA to perform a coronary-coronary bypass over that single distal LAD stenosis. LAD to LAD bypass with a free short segment of the left ITA has been reported only in 2 cases (it was not underlined if it had been the single graft on the LAD) in the largest series of coronary-coronary bypass grafting (Nottin and colleagues ${ }^{3}$ ).

Perhaps in this particular case we had better solutions. The first one was to choose the right ITA for the same procedure (through sinus transversus, it would be very easy to reach the ramus intermedius with the proximal in situ remnant of the right ITA), and we will still have the intact left ITA for an eventual redo procedure. The second possible solution is that perhaps terminoterminal anastomosis (completely excluding the "sick" part of the native coronary artery and thus eliminating potential site of thrombosis) is a better solution in coronary-coronary bypass grafting (if there are no important branches originating from these segments of the coronary artery). 


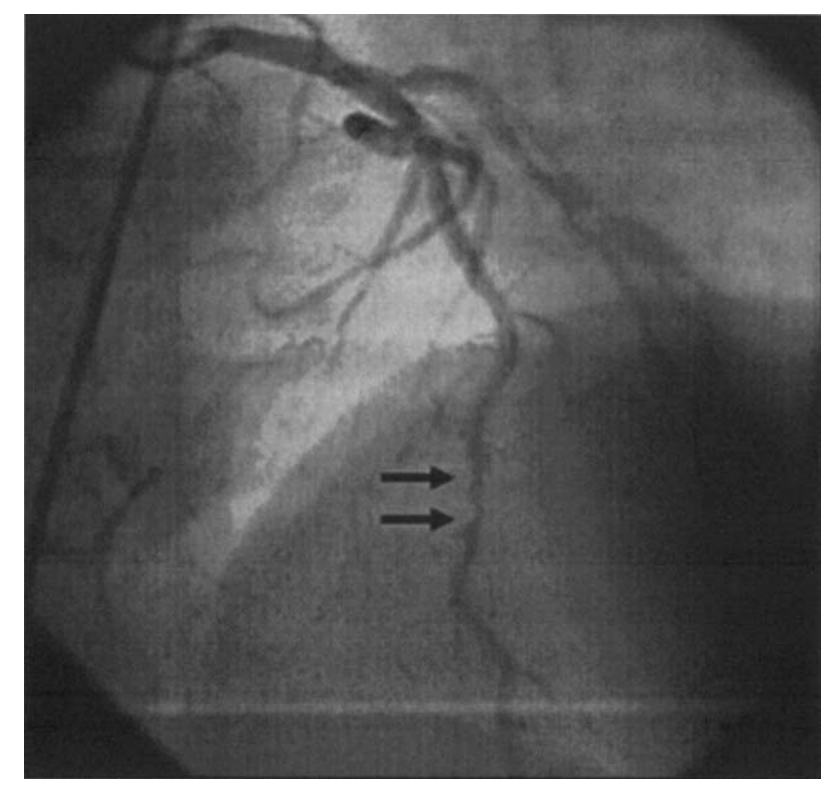

Figure 1. Preoperative angiogram showing severe stenosis on the border zone between the mid and distal third of the large left anterior descending coronary artery (arrows).

In our opinion this technique occasionally might be an attractive approach for bypassing very distal lesions of large coronary arteries (combined with regular arterial or venous grafting of the targeted artery if the proximal stenosis is also present).

\section{References}

1. Effler DB, Favarolo RG, Groves LK. Coronary artery surgery utilizing saphenous vein graft techniques: clinical experience with 224 operations. J Thorac Cardiovasc Surg. 1970;59:147-53.

2. Biglioli P, Almanni F, Antona SC, Sala A, Susini G. Coronary-coronary

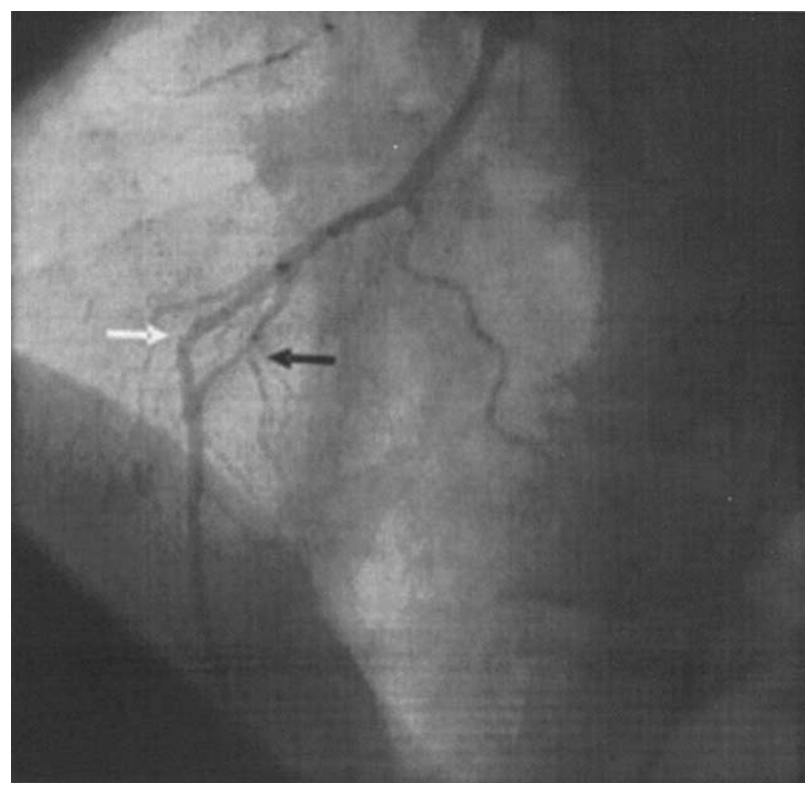

Figure 2. Postoperative angiogram in the same patient (left anterior oblique view) showing severe stenosis on the LAD (black arrow) and a patent coronary-coronary free ITA graft (white arrow).

bypass: theoretical basis and techniques. J Cardiovasc Surg. 1987;28: 333-5.

3. Nottin R, Grinda JM, Anidjar S, Folliguet T, Detroux M. Coronarycoronary bypass graft: an arterial conduit-sparing procedure. $J$ Thorac Cardiovasc Surg. 1996;112:1223-30.

4. Barboso G, Rusticali F. Proximal internal mammary in situ graft and distal coronaro-coronary graft to revascularize left anterior descending coronary artery. Tex Heart Inst J. 2000;27:70-1.

5. Erdil N, Ates S, Demirkilic U, Tatar H, Sag C. Coronary-coronary bypass using vein graft on a beating heart in a patient with porcelain aorta. Tex Heart Inst J. 2002;29:54-5. 